\title{
The Assessment of Learning Difficulties: Designing a Non-Standardized Assessment Test for Preschool and Primary School Age
}

\author{
Kalliopi Papoutsaki ${ }^{1} \quad$ Eleni C. Marseli ${ }^{2} \quad$ Johan Papathansiou $^{3}$ \\ 1. National Kapodistrian University of Athens, Kidathineon, 53, Helioupis, 15566, Athens, Greece \\ 2. Special Education Teacher, Dexamenis 42, Metamorfosi, 14452, Athens, Greece \\ 3. Philologist, Kidathineon, 53, Helioupis, 15566, Athens, Greece \\ * E-mail of the corresponding author: kpapouts@primedu.uoa.gr
}

\begin{abstract}
This article presents a non-standardized assessment test (DTLD-P.S.A.) which was been designed by special education teachers for preschool and primary education children. It is based on the Greek curriculum and aims on identifying the student's cognition and learning deficiencies. Specifically, it is a tool that examines childrens' cognition of listening, speaking, reading, spelling, writing and maths. Teachers may use it in combination with other standardized tests in order to determine precisely types of learning disfunctions. Moreover, the test axes are designed by the authors based on learning difficulties literature so the assessment test (DTLD- P.S.A.) can be used by special education teachers not only to identify children's deficiencies but also to create early and tailor-made interventions depending on their needs and educational deficiencies.
\end{abstract}

Keywords: assessment, learning difficulties, assessment test

DOI: $10.7176 / \mathrm{JEP} / 11-21-01$

Publication date:July $31^{\text {st }} 2020$

\section{Introduction}

Given the complexity of learning difficulties, it is worth evaluating learning disabilities of a multidisciplinary team of experts (Hayes, Dombrowski Shefcyk, \& Bulat, 2018). Effective evaluations should assess all areas related to a student's suspected disability, including: health, vision and hearing, social and emotional status, general intelligence, academic performance, communication abilities, and motor skills (Farrall, Wright, \& Wright, 2015). A multidisciplinary evaluation is carried out by specialists such as doctors (paediatrician, paediatric psychiatrist, otorhinolaryngologist, ophthalmologist), a social worker, a psychologist, a speech therapist and a special education teacher. Thus, it creates a well-rounded diagnostic approach that highlights the development of the student's social; psychometric; psychological profile; as well as the oral speech and level of learning.

Identifying children's difficulties from different scientific dysfunctions contributes to appropriate intervention programs designed by specialists to support pupils in their successful integration in mainstream schools. Assessments by Diagnostic Centres and multidisciplinary teams are conducted through structured or semistructured interviews and the administration of clinical tests. Thereafter, each evaluator will compose a report that will lead to an informed diagnostic and individualized assessment.

Learning assessments aim at identifying the degree of pupils' difficulties either through an initial evaluation that simply reveals the existence of difficulties or through a secondary evaluation that specifies the areas presenting deficiencies and the way these dysfunctions affect school performance (Hayes, Dombrowski, Shefcyk, \& Bulat, 2018). First, teachers detect if there are any issues of learning difficulties and afterwards, they use their programs like Response to Intervention (RtI) to support adolescents with learning difficulties. Nevertheless, if learning difficulties continue to appear, they urge children to go to Public Diagnostic Centers so that they can be identified by multidisciplinary teams. Parents' involvement is also important for the identification of learning difficulties (Rutland \& Hall, 2013), especially when information is provided by expert guidance. Teachers and interdisciplinary teams can diagnose learning disabilities by using standardized and non-standardized tests, as mentioned below.

Unfortunately, there are not enough standardized tests in Greece, especially when it comes to assessing adolescents. In addition, only few educators have been trained and are qualified to conduct such tests. Some of them are (Tzivinikou, 2015): a) "Lambda test", which is a special software that detects specific learning difficulties, in producing and acquiring writing, spelling, reading, comprehension, vocabulary, working memory and speech for pupils aged 10-15 years old. b) Identification of Learning Disabilities by Teachers (I.L.D.T), which investigates the existence of learning difficulties for pupils 8-15 years old, speaking; writing; reading; maths, c) A' Test, which detects reading errors for students aged from 8-15 year old; d) The Detroit Learning Proficiency Test, which is used to assess pupils' proficiency from 4-19 years of age and it investigates articulation, concept association, number sequences, memory, etc. Although these tests are being used, experts create a series of non-standardized assessment tests in order to detect pupils' learning deficiencies and therefore from the outcome to design 
appropriate interventions.

In the existing international literature, there is a number of standardized and non-standardized protocols of evaluations that focus on visual and auditory perception; on the educational environment; on learning difficulties including disorders in reading and writing; and on the ability to handle new technologies so that they can be used in interventions (Hayes, Dombrowski, Shefcyk, \& Bulat, 2018). Furthermore, some well-known tests for diagnosing learning disabilities are the Woodcock-Johnson Tests of Achievement (WJ), the Wechsler Individual Achievement Test (WIAT), the Wide Range Achievement Test (WRAT) and the Kaufman Test of Educational Achievement (KTEA). These tests focus on evaluating reading, writing, and maths.

Both standardized and non-standardized tests can be used as part of a learning assessment. Standardized assessment tests ensure reliability, validity and objectivity of results because large data samples are collected and a set of structured rules follows for administration and scoring. Nevertheless, no-standardized assessment tests of learning difficulties are designed by special education teachers in order to identify learning dysfunctions. Furthermore, in Greece these tests are usually based on the National Curriculum in relation to age cognition, the peculiarities of language and the existing knowledge by evaluating (reading, writing, vocabulary, maths etc.). By combining standardized with non-standardized tests, more reliable conclusions and valuable suggestions to teachers may support students in their difficulties in a better way.

The purpose of this study is to present the process of evaluation that takes place in Greek Public Centers for Adolescents' Diagnosis of Learning Difficulties. Then, it presents the non-standardized assessment test (DTLD) that identifies adolescents' learning difficulties from 11 to 18 years of age. It focuses on for adolescents' deficiencies in reading, spelling, writing and maths, in order to identify the type of learning difficulties and it proposes the appropriate educational program.

\section{Identifying Learning Difficulties}

Identifying students with learning disabilities in preschool and elementary education is a complex and multifaceted process. Initially, teachers screen pupils' skills to determine their disfunctions and they select ways to support them. Then they choose a more detailed evaluation to determine types and areas of learning disabilities which impact them. The non-standardized assessment test (DTLD-P.S.A.) may be used with a standardized assessment test to assess learning difficulties for a more accurate evaluation.

\subsection{Communication skills and personal characteristics}

Initially, the examiner tries to create a friendly atmosphere with the student. The dialogue between them is related to pupil's personal life concerning friendships, family relationships, interests and school context. The interview highlights pupil's basic personal characteristics and communication skills (Table, 1) because all these influences their learning according to recent research (Angelkoska, Stankovska \& Dimitrovski, 2016). The examiner records the results of the evaluation on a five-point scale from low to high (1-5) (Table 1). The asterisk is the reverse score. We add up and multiply the grades by 100 . The score that is below $50 \%$ indicates deficiency.

\begin{tabular}{|c|c|c|c|c|c|c|c|}
\hline & & 1 & 2 & 3 & 4 & 5 & Comments \\
\hline 1.1 & Visual Contact & & & & & & \\
\hline 1.2 & Cooperation with the examiner & & & & & & \\
\hline 1.3 & Attention & & & & & & \\
\hline $1.4^{*}$ & Impulsive & & & & & & \\
\hline $1.5^{*}$ & Shy & & & & & & \\
\hline & Total score & & & & & & Sum of points (A)... \\
\hline
\end{tabular}

${ }^{*}$ Reverse score

Total score:( $\mathrm{A} / 25) \cdot 100=\ldots$

\subsection{Assessment of speech/Oral Assessment}

For all students, language is a central factor for learning. Pupils use speech to express their thoughts and to communicate with others in the school community and in their everyday life. Speech disfunction has a potential impact for children on reaching and may also affect adults or other children. Therefore, this is a consequence of their social, emotional, behavioral and academic well-being (Lindsay, Dockrell, \& Strand, 2007). It's very important to discover all types of learning difficulties on time in order to implement intervention programs. The assessment of speech focuses on the axes below (Table, 2). 


\begin{tabular}{|l|l|l|l|l|l|l|l|}
\hline Table 2. Speech/Talk & 1 & 2 & 3 & 4 & 5 & Comments \\
\hline & & & & & & & \\
\hline 2.1 & Understanding questions & & & & & & \\
\hline 2.2 & Answering questions & & & & & & \\
\hline $2.3^{*}$ & Speech difficulties & & & & & & \\
\hline 2.4 & Oral Vocabulary & & & & & & \\
\hline 2.5 & Narrative ability & & & & & & Sum of points (A)... \\
\hline & Total score
\end{tabular}

* Reverse score

Total score:( $\mathrm{A} / 25) \cdot 100=\ldots$

\subsection{Motor Skills and laterality}

Preschool education is a crucial period for children to develop their motor and literacy skills (Özkür, 2020) and are related to school readiness skills in areas such as language, socialization and cognition (Yang, Ostrosky, Favazza, Stalega, \& Block, 2018). Large motor skills such as marching, climbing, and running, as well as fine motor skills, mostly combine hand and finger manipulation and the dominant side of the body. Through painting the visual-moving coordination and the presence or absence of stabilized laterality - especially hand-related, are evaluated by the (DTLD-P.S.A.) test (Table, 3 ).

Table 3. Motor Skills and laterality

\begin{tabular}{|c|c|c|c|c|c|c|c|}
\hline & & 1 & 2 & 3 & 4 & $\overline{5}$ & Comments \\
\hline 3.1 & $\begin{array}{l}\text { Gross motor skills (motor skills for large objects, strength, } \\
\text { sensory) }\end{array}$ & & & & & & \\
\hline 3.2 & Coordination & & & & & & \\
\hline 3.3 & Reaction Time & & & & & & \\
\hline 3.4 & Pencil grip & & & & & & \\
\hline 3.5 & Dominant side of the body (right or left) & & & & & & \\
\hline & Total score & & & & & & $\begin{array}{l}\text { Sum of points } \\
\text { (A) } \ldots\end{array}$ \\
\hline
\end{tabular}

Total score: $(\mathrm{A} / 25) \cdot 100=\ldots$

\subsection{Memory and Sense of Space and Time}

Both maths and learning to read share several main general features such as long-term and short-term memory, attention to details and existing knowledge (Das \& Janzen, 2004) and this is the reason why it is important to assess these important characteristics. In addition, knowledge of time, spatial and orientation skills are essential to contribute to the acquisition of knowledge. Working memory controls, processes, and maintains relevant information to complete a complex cognitive task that predict not only mathematical achievements but also other general learning abilities (De Smedt et al., 2009). Space and time orientation are skills gained on the preschool age. Understanding the concepts: up-down, in-out, front-back, right-left is evaluated through playful activities. Checking the comprehension of time concepts such as the days of the week, seasons and months of the year are done through the student's personal experiences (routine day-to-day activities), or by scanning the basic season features. The evaluation of space and time concepts are done on a five-level scale (Table 4).

Table 4. Memory and Spatial skills

\begin{tabular}{|l|l|l|l|l|l|l|l|}
\hline & \multicolumn{1}{|l|}{} & 1 & 2 & 3 & 4 & 5 & Comments \\
\hline 4.1 & Long term memory & & & & & & \\
\hline 4.2 & Short term memory & & & & & & \\
\hline 4.3 & Working memory & & & & & & \\
\hline 4.4 & Spatial skills & & & & & & \\
\hline 4.5 & $\begin{array}{l}\text { Knowledge of time (time of the days, the days } \\
\text { of the week, the seasons etc.) }\end{array}$ & & & & & & \\
\hline Total score & & & & & & $\begin{array}{l}\text { Sum of points } \\
\text { (A)... }\end{array}$ \\
\hline
\end{tabular}

Total score: $(\mathrm{A} / 25) \cdot 100=\ldots$

Children with learning difficulties may have hearing or vision impairment (Dominguez \& Carugnom, 2020) which influence their reading and writing. Visual assessment, sound perception and demarcation (Table, 5) are parts of the assessment test (DTLD-P.S.A.). 
Table 5. Visual and Sound perception

\begin{tabular}{|l|l|l|l|l|l|l|l|}
\hline & 1 & 2 & 3 & 4 & 5 & Comments \\
\hline 5.1 & Visual perception & & & & & & \\
\hline 5.2 & Visual demarcation & & & & & & \\
\hline 5.3 & Sound perception & & & & & & \\
\hline 5.4 & Sound demarcation & & & & & & \\
\hline 5.5 & Visual motor coordination & & & & & & \\
\hline & Total score & & & & & & Sum of points (A)... \\
\hline
\end{tabular}

Total score:( A/25).100=...

The usual criteria for diagnosing reading disability include deficiencies in phonological awareness, word recognition and decoding skills (Dominguez \& Carugnom, 2020). Phonological awareness typically develops around preschool years and is predictive for later reading outcomes (Storch \& Whitehurst, 2002). Recognizing letter names and their corresponding sounds is perhaps the best predictor for future rehabilitation of reading ability (Schatschneider, Fletcher, Francis, Carlson, \& Foorman, 2004). The acquisition of phonological awareness skills and the knowledge of letters are detected on Table 6.

Table 6. Pre-writing/reading skills (pre-school ages)

\begin{tabular}{|l|l|l|l|l|l|l|l|}
\hline & 1 & 2 & 3 & 4 & 5 & Comments \\
\hline 6.1 & Phonological awareness & & & & & & \\
\hline 6.2 & Letter formation & & & & & & \\
\hline 6.3 & Name writing & & & & & & \\
\hline 6.4 & Acquisition of Letter Naming knowledge & & & & & & \\
\hline 6.5 & Acquisition of letter-sound knowledge & & & & & & \\
\hline & Total score & & & & & & Sum of points (A)... \\
\hline
\end{tabular}

Total score: $(\mathrm{A} / 25) \cdot 100=\ldots$

The literature of early math skills development emphasizes that at the beginning of primary school, this type of learning involves main skills related to numerical cognition, quantity understanding, recognition of numbers and counting skills (Geary, Hamson, \& Hoard, 2000). The development of communication, prewriting, prereading skills, as well as the degree of the student's cooperation and concentration, the development of gross and fine motor skills, memory, space and time orientation and the letter or number formation are basic skills which focus on the Greek Curriculum of pre-school education. Our evaluation tool investigates the pupil's understanding of the concept of measurement (big-small, thin-thick, tall-short), as well as sequencing such as lining up objects from smallest to biggest and vice versa. The assessment test (DTLD-P.S.A.) identifies sequencing, position and direction, categorizing, quantity, shapes and color skills (Table, 7).

\begin{tabular}{|c|c|c|c|c|c|c|c|}
\hline & & 1 & 2 & 3 & 4 & 5 & Comments \\
\hline 7.1 & Sequencing (from small to large and vice versa) & & & & & & \\
\hline 7.2 & Categorization (size, type etc.) & & & & & & \\
\hline 7.3 & Quantity & & & & & & \\
\hline 7.4 & Colors & & & & & & \\
\hline 7.5 & Shapes & & & & & & \\
\hline & Total score & & & & & & Sum of points $(\mathrm{A})$.. \\
\hline
\end{tabular}

Total score: $(\mathrm{A} / 25) \cdot 100=\ldots$

\section{Identifying Learning Difficulties in Primary Education}

Reading and writing are very important skills used by people for communication purposes, teaching, thinking and learning skills. Phonological awareness is an oral language skill which is prerequisite for correlating sounds with letters and accomplishing in writing them (Anthony \& Francis, 2005). Writing is evaluated through texts that are instructed to be copied by students and dictation assessment which the student is supposed to write words or sentences that are verbally dictated from the examiner. Legible writing, spacing between words, replacement, transposition, omissions of letters or syllables, inversions, anagrams, mirror writing are also being evaluated. The assessment of writing focuses on the use of the structural elements of the sentence, the structure of the text, the relativity of the content towards the topic, and the length of the text in relation with the pupil's age. The student's grammatical knowledge is evaluated in relation with the pupil's age, the tools that have been used on his teaching, existing knowledge from part of his speech, and the inflection of nouns, adjectives and verbs (Table, 8). 
Table 8. Writing skills

\begin{tabular}{|l|l|l|l|l|l|l|l|}
\hline & 1 & 2 & 3 & 4 & 5 & Comments \\
\hline 8.1 & Phonological awareness & & & & & & \\
\hline 8.2 & Spelling & & & & & & \\
\hline 8.3 & Copying words & & & & & & \\
\hline 8.4 & Dictation & & & & & & \\
\hline 8.5 & Written Expressions & & & & & & \\
\hline & Total score & & & & & Sum of points (A)... \\
\hline
\end{tabular}

Total score:( A/25).100=...

Reading skills require the activation of the cognitive system and a range of complex knowledge such as selective attention, eye focus, visual information retention of short memory (Nikolopoulos, 2007). Therefore, the evaluation focuses not only on the apparent difficulties, but also on their causes, in order to characterize the type of learning difficulties. Reading skills require acquisition of phonemic and phonological awareness, fluency, vocabulary and comprehension (Tzivinikou, 2015). Weak readers usually have difficulty in the speed and accuracy of the words they read. These dysfunction problems may negatively affect the comprehension dimension which is the main purpose of reading (Kim, Park, \& Wagner, 2014).

Adolescents read texts that have been chosen for them and which are related to their mental age in order to evaluate their reading skills. The reading evaluation is for the examinee to identify as letters; correct expression of phoneme, omissions, grammatical or syllable substitutions, distinction of letters or spelling. Nevertheless, speed at reading and comprehension are thoroughly checked during the examination as well. Adolescents read (real and false) words and texts which range from 10 to 12 rows approximately 100 words. Then they answer some questions to evaluate their ability of comprehension (Table 9).

\begin{tabular}{|c|c|c|c|c|c|c|c|}
\hline & & 1 & 2 & 3 & 4 & 5 & Comments \\
\hline 3.1 & Phonological awareness & & & & & & \\
\hline 3.2 & Letter Identification & & & & & & \\
\hline 3.3 & Word Identification & & & & & & \\
\hline 3.4 & Fluency in Reading & & & & & & \\
\hline 3.5 & Comprehension & & & & & & \\
\hline
\end{tabular}

Total score: $(\mathrm{A} / 25) .100=\ldots$

Writing and spelling are skills that pupils learn at an early age and are some of the permanent learning factors (Duran \& Karatas, 2019). Students with writing difficulties make a lot of mistakes on simple words and grammar because it is very difficult for them to automate grammar rules. More severe dysfunctions are as follows: letters cannot be written correctly; mixing small and large letters; incomplete letters; writing the written manuscript in different directions; irregular letter shapes and sizes (Akyol, 2011), irregular space between letters and words, irregular size of the letters, letters are not aligned on the line (Graham, Santoro, Berninger \& Struck, 2006). All these dysfunctions affect legibility.

Teenagers write a text which is dictated to them and the examiner evaluates their writing skills, their speed of writing, and their pencil handling, (Table 10).

\begin{tabular}{|l|l|l|l|l|l|l|l|}
\hline Table 10. Maths skills & 1 & 2 & 3 & 4 & 5 & Comments \\
\hline 10.1 & Perception of numbers & & & & & & \\
\hline 10.2 & Perception of symbols & & & & & & \\
\hline 10.3 & Math Calculation (integers, decimals, fractional numbers) & & & & & & \\
\hline 10.4 & Mathematical thinking & & & & & & \\
\hline 10.5 & Time, years, century e.t.c. & & & & & \\
\hline & Total score & & & & & & Sum of points (A)... \\
\hline
\end{tabular}

Total score: $(\mathrm{A} / 25) .100=\ldots$

At the end of the assessment, the teacher observes and studies all the above axes and subscales, focusing on the student's deficiencies and characterizes if the difficulty is related to educational deficiencies or learning difficulties. The teacher records the percentage and the types of errors on a ten-point scale from low to high (1-5). The total result is converted to a percentage score that shows weakness if the score is below 50\%, (Table 11). 
Table 11: Total percentage of subscales: Identifying Learning Difficulties in Preschool Age and school age

\begin{tabular}{|l|l|l|l|l|l|l|}
\hline & 1 & 2 & 3 & 4 & 5 & Comments \\
\hline Communication skills and personal characteristics & & & & & & \\
\hline Speech & & & & & & \\
\hline Motor Skills and laterality & & & & & & \\
\hline Memory, Space and Time Awareness & & & & & & \\
\hline Visual and Sound perception & & & & & & \\
\hline Pre-writing (pro-school age) & & & & & & \\
\hline Pre-maths skills (pro-school age) & & & & & & \\
\hline Writing skills (school age) & & & & & & \\
\hline Reading skills (school age) & & & & & & \\
\hline Maths skills (school age) & & & & & & \\
\hline Total score & & & & & & Sum of points(A).... \\
\hline
\end{tabular}

\section{Conclusion}

The above-mentioned non-standardized test (DTLD-P.S.A.) aims at identifying learning difficulties of preschool and elementary education children. Furthermore, it helps teachers to evaluate children's deficiencies, to design and implement customized intervention programs in classrooms or to create the Individualized Education Plans (IEP), and to determine what supports best students to succeed in school. It evaluates communication skills, such as visual contact, co-operation and levels of distraction, speech ability, long and short-term memory, visual and sound perception, speech, reading, writing and maths skills. Considering Greek standardized assessment tests of learning difficulties, the Greek Curriculum, the native language and Culture, we have designed the (DTLD-P.S.A) test in order to make it easy, fast and reliable to use. This test can be initially given to students by teachers in order to identify types of learning difficulties which results in getting input to design an intervention for rehabilitation. In this way, teachers could have some thoroughly detailed information about any kind of disfunctions students may have and they may provide them with high level services to overcome their difficulties and improve their academic performance. In this study we have presented only the axes because the items are related with the special language characteristics.

Using standardized tests requires training and experience. On the other hand, using non-standardized tools does not require training. Moreover, they are easy to use and they evaluate specific areas according to the students' individualized needs. When non-standardized tests are available, teachers construct assessments on their own, which may not be in line with the standard assessment criteria and which may lack in proper evaluation. Nevertheless, we are hoping that using the (DTLD-P.S.A) test, which has been designed taking into account the axes of standardized tests will help teachers to screen and evaluate students' progress and will help them design appropriate interventions to support and help children gaining academic success. This involves making "reasonable adjustments" by providing support for students with disabilities, to ensure their full participation and to provide them with equal opportunities in the school context (Mbuvha, 2019).

\section{References}

Anderson, R. \&Faust, G.(1975). Educational Psychology. The Science of Instruction and Learning. Dodd, Mead $\&$ Co. New York.

Anthony, J. L., \& Francis, D. J. (2005). Development of phonological awareness. Current Directions in Psychological Science, 14 (5), 255-259

Ahmedi. V. (2019). Teachers' Attitudes and Practices Towards Formative Assessment in Primary School. Journal of Social Studies Education Research. 10(3), 161-175.

Arai, T., Aiyama, Y., Sugi, M. \& Ota, J. (2001), "Holonic Assembly System with Plug and Produce", Angelkoska, S. Stankovska, G \& Dimitrovski, D. (2016). The Personal Characteristics Predictors of Academic Success. Education Provision to Every One: Comparing Perspectives from Around the World BCES Conference Books, 14(1). 262-268.

Bergeson, T., Davidson, C., Mueller, M., \& WilliamsAppleton, D. (2008). A guide to assessment in early childhood: Infancy to age eight. Office of the Superintendent for Public Instruction, Washington State. Retrieved from http://www.k12.wa.us/ EarlyLearning/pubdocs/assessment_print.pdf

Black, P., \& Wiliam, D. (1998). Assessment and classroom learning. Assessment in Education. 5(1), 7-74.

Das, J. \& Janzen, C. (2004). Learning Math: Basic concepts, math difficulties, and suggestions for intervention. Developmental Disabilities Bulletin, 32 (2). 191-205.

De Smedt, B., Janssen, R., Bouwens, K., Verschaffel, L., Boets, B., \& Ghesquière, P. (2009). Working memory and individual differences in mathematics achievement: A longitudinal study from first grade to second grade. Journal of Experimental Child Psychology, 103(2), 186-201. 
Dominguez, O. \& Carugnom, P. (2020). Learning Disability. StatPearls Publishing LLC. https://www.ncbi.nlm.nih.gov/books/NBK430685

Geary, D. C. (1994). Children's mathematical development: Research and practical applications. Washington, DC: American Psychological Association

Geary, D. C., Hamson, C. O., \& Hoard, M. K. (2000). Numerical and arithmetical cognition: A longitudinal study of process and concept deficits in children with learning disability. Journal of Experimental Child Psychology, $77(3), 236-263$

Hayes, A. Dombrowski, E., Shefcyk, A. \& Bulat, J. (2018). Learning Disabilities Screening and Evaluation Guide for Low- and Middle-Income Countries. U.SA. RTI Press.

Klute, M., Apthorp, H., Harlacher, J., \& Reale, M. (2017). Formative assessment and elementary school student academic achievement: A review of the evidence. Washington, DC: U.S. Department of Education, Institute of Education Sciences, National Center for Education Evaluation and Regional Assistance, Regional Educational Laboratory Central. Retrieved from http://ies.ed.gov/ncee/edlabs.

Lindsay, G., Dockrell, L., \& Strand, S. (2007). Longitudinal patterns of behaviour problems in children with specific speech and language difficulties: child and context factors. British Journal of Educational Psychology, 77(4), 811- 828. http://dx.doi.org/10.1348/000709906X171127

Lyon, C., \& Leusner, D. (2008). Research rationale for the Keeping Learning on Track ${ }^{\circ}$ Program: Integrating assessment with instruction through Teacher Learning Communities. PEAr-08-01. Princeton, NJ: Educational Testing Service.

Mbuvha, T. (2016). Kinds of Support Offered by the Disability Unit to Students with Disabilities at Institutions of Higher Learning in South Africa: A Case Study of the

University of Venda. Journal of Student Affairs in Africa. 7 (2). 57-73. DOI: 10.24085/jsaa.v7i2.3825 57

Scott McConnell, S. \& Wackerle-Hollman, A. (2016). Can We Measure the Transition to Reading? General Outcome Measures and Early Literacy Development From Preschool to Early Elementary Grades. AERA Open. 2(3). 1-15. DOI: 10.1177/2332858416653756

Overton, T. (2012). Assessing learners with special needs (7th ed.). Upper Saddle River, NJ: Pearson Education

Özkür, F. (2020). Analyzing Motor Development and Emergent Literacy Skills of Preschool Children. International Education Studies. 13(4). 94-99.

Schatschneider, C., Fletcher, J. M., Francis, D. J., Carlson, C. D., \& Foorman, B. R. (2004). Kindergarten prediction of reading skills: A longitudinal comparative analysis. Journal of Educational Psychology, 96(2), 265-282. https://doi.org/10.1037/0022-0663.96.2.265

Storch, S. A., \& Whitehurst, G. J. (2002). Oral language and code-related precursors to reading: Evidence from a longitudinal structural model. Developmental Psychology, 38, 934-947. https://doi.org/10.1037/00121649.38.6.934

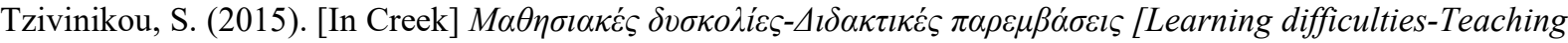
interventions]. Retrieved from: http://hdl.handle.net/11419/5332

Yang, H. W., Ostrosky, M. M., Favazza, P. C., Stalega, M. \& Block, M. (2018). Embedding motor activities into inclusive preschools. Young Exceptional Children.Advance online publication. doi:10.1177/1096250618783994

K. Papoutsaki studied Special Education at the National Kapodistrian University of Athens. She teaches at the Hellenic Open University and the Department of Special Education of the University of Thessaly in Greece. She has worked as a special education teacher in Primary Schools and she has been a teachers' Consultant for over 10 years. At present she is working at the Greek Public Center for Diagnosis of Learning Difficulties of Adolescents, which is housed in the National Children's Hospital and is under the auspices of the National and Kapodistrian University of Athens. She has published a lot of articles and books about learning difficulties and special education.

E. Marseli is a special needs teacher in primary education. She graduated from the University of Thessaly and has been working in public special needs schools in Greece and the United Kingdom for the last nine years. She also got a bachelor degree in Psychology from the University of Hertfordshire UK. She has actively participated in many workshops and seminars as a spokesman's presenting interventions to students' behaviour in primary education, giving counsel to parents and advising teachers on how to cope and communicate with parents..

J. Papathanasiou studied Greek Literature at the University of Crete and she has got an MSc in Special Education at the Open University of Cyprus. She teaches children and adolescents with learning disabilities. She has published several articles about learning disabilities. 